\title{
Papulopustular Rash
}

National Cancer Institute

\section{Source}

National Cancer Institute. Papulopustular Rash. NCI Thesaurus. Code C80119.

Skin eruption consisting of papules and pustules, most often appearing in the face, scalp, and upper trunk. It is usually caused by corticosteroids or epidermal growth factor receptor inhibitors. 